\title{
Ancient Textual Sources on Ligamentum Teres: Context and Transmission
}

\author{
S.V. Arkhipov ${ }^{1}$, I.V. Prolygina² \\ 1 Laboratory of Clinical Physiology and Biomechanics, Federal State Budgetary Institution N.N. Priorov \\ National Medical Research Center of Traumatology and Orthopaedics of the Ministry of Health of the Russion \\ Federacion, Moscow, Russia \\ 2 A.l. Yevdokimov Moscow State University of Medicine and Dentistry, Moscow, Russia
}

\author{
CORRESPONDING AUTHOR: \\ Sergey V. Arkhipov \\ Laboratory of Clinical Physiology \\ and Biomechanics \\ Federal State Budgetary Institution \\ N.N. Priorov National \\ Medical Research Center \\ of Traumatology and Orthopaedics \\ of the Ministry of Health of the Russion \\ Federacion \\ 10 Priorova Street, Moscow, Russia, 127299 \\ E-mail: archipovsv@gmail.com \\ DOI: \\ 10.32098/mltj.03.2020.27
}

LEVEL OF EVIDENCE: $1 \mathrm{~A}$

\begin{abstract}
SUMMARY
Background. One of the least researched anatomical structures of the human body is the ligament of head of femur, most often referred to as ligamentum teres. The history of the nomination of this term, medical contexts of its use, the etymology and the first synonyms are not sufficiently understood.

Purpose. The purpose of the article is to present the most complete collection of evidence from ancient medical authors about the term ligamentum teres, trace the history of its nomination and analyze the gradual changes in the level of knowledge about the anatomy, mechanical and geometric properties of this structure, its pathology and treatment methods.

Methods. The study is based on an interdisciplinary approach, comprising a combination of linguistic and medical analysis of the texts in ancient Greek and Latin, which contain references to ligamentum teres.

Results. Text analysis showed that ligamentum teres was known in Palestine at the time of the compilation of the Book of Genesis. In the medical sources written by the Greek physicians, references to it and the description of its properties and role date back to the V-IV cent. BC. The study of textual sources and their medical contexts showed the evolution of the development of this term from the general concept of "sinew" to a narrowly defined "ligament" with detailed qualitative characteristics of the structure and function of this anatomical structure. It has been noted that since ancient times ligamentum teres has been recognized as an important element of biomechanics of hip joint and the action of walking.

Conclusions. This work will serve as a basis for further studies and treatment of the interesting and mysterious structure that is ligamentum teres - a true ligamentum incognitum.
\end{abstract}

\section{KEY WORDS}

Ancient medicine; ancient traumatology; Galen; Hippocrates; hip joint; ligamentum capitis femoris; ligament of head of femur; ligamentum teres.

\section{INTRODUCTION}

Recently, the attention of researchers and clinicians has been increasingly attracted by the under-investigated anatomical structure ligamentum teres (LT), which connects the femoral head and the acetabulum $(1,2)$. Despite the fact that LT has been known for over three millennia, its anatomy and function have not been fully studied and continue to be refined (3-6). For instance, its role in the musculoskeletal system is still not clear, and opinions on this issue are often very divided (7-10). Some authors concluded that LT is a rudimentary structure of hip joint $(\mathrm{HJ})(11,12)$. The contemporary studies, however, regard it as a fully functional ligament with the strength comparable to that of the anterior cruciate ligament of the knee joint (8). The recent data show the importance of LT as an HJ-stabilizing structure, which is involved in maintaining vertical positions $(13-17)$. LT is currently recognized as a potential source of pain as well as mechanical symptoms in $\mathrm{HJ}$, including gait impairment 
(3,18-24). The evasive knowledge about LT is reflected in dozens of its synonyms, with its original names unknown not only to laymen, but even to experts $(7,23,25)$. In some publications, including those claiming to be comprehensive, the earliest extant evidence regarding LT is, in our opinion, insufficiently covered $(26,27)$. Therefore, this work attempts to provide the most complete review of LT-related sources from ancient authors. We believe that this will make it possible to clarify the earliest period of studying LT and knowledge about it and will help experts to better understand the basis of their research.

\section{MATERIALS AND METHODS}

This study is based on an interdisciplinary approach involving a combination of linguistic and medical knowledge. The original fragments of ancient physicians on LT, written in ancient Greek and Latin, as preserved in the electronic platform Thesaurus Linguae Graecae (University of California, Irvine, CA, USA), were investigated in relation to the modern views on normal and pathological anatomy of this anatomical element, its role in the musculoskeletal system, its mechanical and geometric properties. The pathology treatment methods are also considered.

This work submits to the ethical standards of the Muscles, Ligaments and Tendons Journal (28).

\section{RESULTS}

\section{Biblical tradition: Genesis 32:32}

Perhaps the earliest known mention of LT is found in the Book of Genesis. The period of the compilation of the Pentateuch, which includes the Book of Genesis, can be approximated only with a very relative accuracy. Given the period of codification and the long oral tradition of its sources, it can be dated to the period of the XIV-VI centuries BC (29-31). In this ancient written source, LT is mentioned in the context of the narrative of the Patriarch Jacob wrestling with God and acquiring the name of Israel. Genesis 32:32 says:

«That is why to this day the Israelites do not eat the thigh sinew which is at the hip socket: because he had struck Jacob at the hip socket on the thigh sinew».

NJB.

In the Masoretic text of the Biblia Hebraica, the expres-

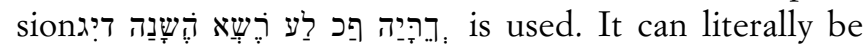
translated as "the thigh sinew, which [is located] in the

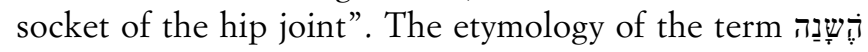

(bannasheb) is unclear, and the term (gid) is translated as "sinew" (32).

The authors of the Septuagint (LXX), the Greek translation of the Old Testament (III-I cent. BC in Alexandria) from a pre-masoretic version of the Hebrew text, rendered this text

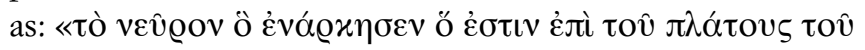

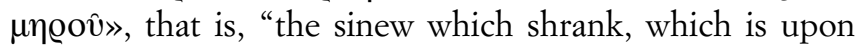
the hollow of the thigh" (KJV). The translators, apparent-

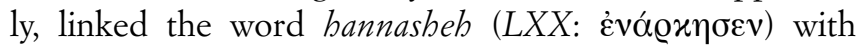
the root nashah, interpreting it as "to dislocate", "become weak". From the point of view of modern medicine, it can be assumed that in this case we are talking about damage to acetabulum.

The Latin translation of the Bible, the so-called Vulgate, was completed in the IV century AD by St. Jerome, who translated the Bible directly from Hebrew, but was also very familiar with the Greek text of the Septuagint. This fragment described above is conveyed there as follows: nervum qui emarcuit in femore Iacob, "sinew, which weakened in Jacob's thigh". The Hebrew, the Greek and the Latin texts formed the basis for all the subsequent translations into other ancient and modern languages, as well as for patristic, Jewish and modern biblical comments.

Most biblical commentators agree that Genesis 32:32 mentions the sciatic nerve (nervus ischiadicus), the large nerve trunk of the femoral region, which the Greeks called the Achilles tendon (33-35). Other commentators argue that this word refers to the tendon which holds the head of the femur in the acetabulum, along with the surrounding muscles (36). However, neither in the Pentateuch nor in the other Old Testament books there is any further mention of the anatomical structure of $\mathrm{HJ}$, so it is difficult to establish the exact meaning. In our opinion, consistent with the point of view of some other authors (37), this "sinew" is LT, since no muscle tendons are attached in acetabulum and no large nerve trunks are present. Moreover, the transverse section of the proximal end of LT reveals an approximately cylindrical shape, resembling a tendon or a nerve fragment.

The quote from Genesis 32:32 has an important historical and medical implication for anatomy, traumatology, and biomechanics of HJ. This fragment is one of the earliest mentions of $\mathrm{HJ}$ and, possibly, the first written reference in the history of mankind to a special anatomical element in it, that is, LT. It can be assumed that in Palestine of the biblical times it was known that LT could be damaged by an indirect trauma mechanism, for example, by a forced hip rotation, its subluxation and dislocation. This is also the first known description of one of the earliest visual symptoms of LT injury, that is, lameness. In addition, Genesis provides perhaps the first "medical history" of HJ and LT injury. As befits the modern medical record, the patient's 
name, marital status, personal characteristics, approximate age and working conditions are described, as well as the circumstances, time and location of the injury, localization of the damage, its mechanism, consequences and pathomorphology. From further narration (Genesis 50:2), we learn that the Patriarch Jacob was posthumously embalmed by Egyptian physicians, first mentioned in Genesis as representatives of a specific and separate profession (25). This allows us to conclude that the diagnosis of LT injury could be morphologically verified by means of some prototype of pathological study. From the biblical text it follows that the resulting biomechanical ambulation disorder turned out to be persistent, and the cause of it was damage to $\mathrm{HJ}$, or, more precisely, LT.

Paradoxical as it may seem, an analysis of this ancient, not at all medical source, allows us to make a significant assumption for modern science: LT is an important functional relation of $\mathrm{HJ}$, and only with it intact, normal-walking can be achieved, making LT a part in the organization of this type of human locomotion.

\section{The terms vev̂@ov/nervus: classical tradition}

Ancient authors of the Classical period did not initially distinguish between such anatomical structures as tendon, ligament and nerve neither in terminology, nor, apparently, in practice, as indicated by the absence of special names for each one of them. There was a single term tò vev̂ @ov, to which the multivalent term "sinew" corresponds most closely. It can mean "tendon", "ligament", "nerve", as well as "vein" and "artery". The Latin term nervus has the same

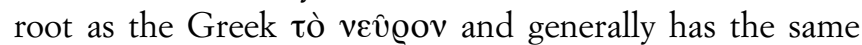
initial meanings as "string", "thread", "fiber", from which, by metaphorical transfer, they acquired the medical meaning of "white fibrous threads that support the muscles, connect the joints and transmit nerve or motor impulses" (38). The term tò vev̂@ov, in the meaning of "sinew", which can mean "tendons", "ligaments", and "muscles", and possibly "large nerves" and "blood vessels"), is found in Homer's Iliad:

«[...] Phylides, taking note / That bold Amphiclus bent at him, prevented him, and smote / His thigh's extreme part, where of man his fattest muscle lies, / The nerves torn with bis lance's pile, and darkness clos'd his eyes».

Iliad XVI: 313-316.

Hippocrates (born $460 \mathrm{BC}$ ), expounding in the treatise Places in Man on certain types of sinews, mentions those that are "connected with joints," meaning tendons, and "hollow veins", that is, blood vessels, lymphatic vessels, various ducts and bronchi (De loc. in hom., 5) (39).
Apparently, it is about the articular ligaments connecting two, and in some cases more, bone organs, that Aristotle (IV cent. BC) writes in the History of Animals, mentioning that:

«They aid in the support of the body $<\ldots>$ The sinews around the joints have not received any name, for all the bones where they are contiguous are bound together by the sinew (vev́oors). And there are many sinews round all the bones».

Hist. anim. III, V, 50 (515b 11).

The distinction between nerves, muscles, tendons and ligaments first appears only in the anatomy of the first Alexandrian school (III cent. BC). Herophilus (IV-III cent. BC) did not yet have a clear distinction between nerves and muscles, since he recognized both muscles and nerves as organs of voluntary movement (40). The idea of the physiology of muscle contraction first appears in Erasistratus (IV-III cent. BC). He believed that muscle contracted under the influence of the pneuma that is contained within, and the nerves were deprived of any function in voluntary movement (Gal. De loc. aff.) (41,42). In terminology, Erasistratus distinguished between sensory ( $\alpha i \sigma \theta \eta \tau \iota x \alpha ́)$ and motor

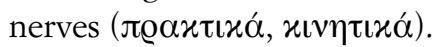

Apparently, it was Pliny the Elder (1st cent. AD) that used the Latin term nervus as applied to tendons in Natural History. When speaking about the Achilles tendon, he calls it a "sinew" (nervus), which is defined as "flat" (platys) (Hist. nat. 26, 90). He uses the same term with reference to ligaments:

«In all animals they (nervi) are fastened to the lubricous surface of the bones, and so serve to fasten those knots in the body which are known as articulations or joints, sometimes lying between them, sometimes surrounding them, and sometimes running from one to the another; in one place the are long, and in another broad, according as the necessity of each case may demand».

Hist. nat. 11, 217.

Here we have one of the first classifications of ligaments and the first use of the concept of "round" (lat. teres, rotundum) used to describe ligaments in general. As for the nerves, since they do resemble thin tendons, the ancient anatomists thought that they served for flexion and extension of various parts of the body.

Aulus Cornelius Celsus (25 BC - 50 AD) writes about a pathology of HJ ligaments, called "sinews" (nervis), which are damaged and stretched when hip is dislocated:

"When the bone is replaced nothing further need be done, but the patient must be kept in bed for a rather long time or 
the thigh may become displaced again on moving while the sinews (nervis) are still relaxed».

$$
\text { De med. VIII, 20, } 8 .
$$

Galen of Pergamon (II-III cent. AD) provides a more clear systematization of various kinds of sinews. He often accompanies the term vevooov with clarifying definitions or gives one-word synonyms. In the treatise On Bones for Beginners Galen describes three types of sinews: those originating in

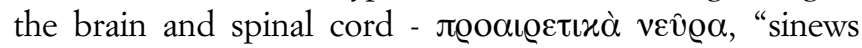
responsible for voluntary movements"; originating in bones

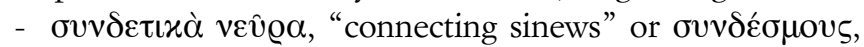

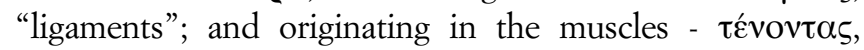
"tendons" (De oss. ad tir., 24) (41). Speaking in the treatise On Movement of Muscles on the origin of this term, he associates it with the verb vev́evv, "bow one's head, nod" (De motu musc. 1, 1) (41).

13 centuries later, the etymology and medical ambiguity of the term nervus would be discussed by Andreas Vesalius (1514-1564) in his anatomical atlas On the Fabric of the Human Body (1543), in which he'd accept and repeat the definitions of Galen (De bumani fabr. corp. IV, 1). The modern etymological dictionaries consider this interpretation to be a paretymology and correlate the term vev̂oov with the verb véw, "spin" (43), implying the pulling and twisting of yarn from a tuft of wool.

In a later treatise, On the Usefulness of Parts of the Body, Galen already clearly differentiates both the terms and the functions of ligaments and nerves:

«Where a member needs only a connection, there is only a ligament ( $\sigma u v v \delta \varepsilon \sigma \mu \mathrm{s})$, and where it needs only a sensation, there is only a nerve (vevoov). On the contrary, in organs that could benefit from having voluntary movement, you can see them together: a nerve that transmits an order received from the center of thought and determines the principle of movement, and a ligament that provides the nerve with its power to maintain the joints brought into a state of movement».

$$
\text { De usu part. XII, 3, } 7 \text { (41) }
$$

\section{Ancient medical authors (prior to Galen) about ligamentum teres}

In the history of ancient medicine, LT and its topographic anatomy were first mentioned in the treatise Instruments of Redactions by Hippocrates:

«The femur itself bends outward and forward; its head is a round epiphysis which gives origin to ligament (vevoov) inserted in the acetabulum of the hip-joint. This bone is articulated somewhat obliquely, but less so than the bumerus».

Vectiar. 1 (39).

Indeed, LT attaches to the bottom of acetabular fossa at an acute angle, and its counterpart in the shoulder joint is at a right angle. This so-called "ligamentum teres in the shoulder joint" is clearly visible in certain animal species and is otherwise called ligamentum gleno-bumerale (syn. lig. interarticulare bumeri) $(44,45)$. Its counterpart in humans is not very prominent and is called ligamentum glenobumerale superius $(46,47)$. This fragment indirectly indicates that Hippocrates studied the anatomy primarily by dissecting animal bodies. It should be noted that Hippocrates describes LT as an already well-known element, noting its location and attachment to the bone of HJ. How could Hippocrates, who did not dissect humans, observe LT? It is likely that he could have seen this anatomical element when examining a patient with an open hip dislocation. This pathology is a rare type of trauma that currently occurs with high energy trauma as a result of a car accident and fall $(48,49)$. Similar high-energy traumas could be observed in the time of Hippocrates, for example, when one fell from height, was hit by a large animal or by a heavy part of rigging of a ship.

In Galen's IV commentary on Hippocrates' book On Joints, a fragment of the treatise On External Treatment by the Greek physician Heraclides of Tarentum (III-II cent. BC) was preserved (50). Speaking about the reduction of a dislocated hip, he gives the earliest description of the pathology of LT resulting from this injury:

«Those who believe that the hip does not remain set because the ligament (vevoov) connecting the femur to the acetabulum is torn, do not know things of general knowledge, when expressing their negation. For neither Hippocrates nor Diocles would have described the reductions, and neither would Phylotimus, Evenor, Nileus, Molpis, Nymphodorus and some others. And we have achieved this goal [reduction] in two children, although in adults the joint is dislocated again more often. This case should be judged not from hearsay, but since the thigh sometimes remains [set], it must be assumed that this ligament does not always rupture, but that it stretches and contracts again [...]» In Hipp. de artic. IV, 40 (41).

From this fragment we learn that in the days of Heraclides of Tarentum physicians already knew not only about LT, its attachment to the hip and the acetabulum, as well as its connecting function, but also about its injury incurred by a traumatic hip dislocation. It is safe to assume that the author personally performed anatomical studies of both normal and pathologically altered HJ. He also opined that LT could 
stretch and contract, thus remaining intact after hip dislocation. A few modern studies partly confirm the Heraclides of Tarentum's guess and indicate the possibility of LT recovery after hip dislocation $(18,51,52)$.

There is an extant fragment of the text by another Greek surgeon, Hegetor, a native of Alexandria (II century BC). The Apollonius of Citium's (90-15 BC) commentary on the Hippocrates' book On Joints provides an excerpt from it: «In the book "On Causes", Hegetor mentioned hip dislocation in the following passage: "Why don't those who rely only on experience seek to find any other [way] of reduction the femoral head for those who have it dislocated, in such a way that every time it dislocates, it can be reset? After all, we can observe that the lower jaw, and the humeral head, the elbow, and the knee, and each finger, and the majority of joints that may dislocate, can be reset in a similar way. For, not being able to understand why this joint only, after dislocation and repeated reduction, won't remain in its place, and seeing what often happens with other joints, they will probably come to the conclusion that there might be a better way of reduction, after which the joint will stay [set]. If they only thought about the reason from the point of view of anatomy, - because the femoral head is a foundation for the ligament (vevoov) [of femoral head], which grows into the middle of acetabulum; and when it remains [intact], the femur cannot dislocate, but when it ruptures, the hip cannot provide a firm connection; and when there is a lack of connection, the joint cannot remain in place. Since the reason has been clarified, one can refrain altogether from a reduction of a dislocated femur and not make attempts doomed to failure».

In Hipp. de art. (53).

Hegetor repeats the previously known information about LT about the areas of its attachment and its anchoring role, but, unlike Heraclides of Tarentum, he is somewhat pessimistic about the possibility of reduction of hip dislocation. Perhaps the author in his practice encountered cases of complicated dislocation accompanied by a fracture of the wall of acetabulum or femoral head, or perhaps he was not able to differentiate the dislocation from the femoral neck fracture. For these reasons, his attempts to "set it" were not successful, which served as the basis for therapeutic pessimism.

Further, Apollonius of Citium expresses its own opinion on this issue:

«If the dislocated and displaced hip could not remain in place, then the physician [Hippocrates] would have clearly indicated the incurability of this case, so that we would not be led astray. Don't those who hold the opposite opinion know about the nature of joints, ligaments and the teachings about these things in general? After all, the physician considered the cause of the mild or, on the contrary, complex displacement and reduction of the joints to lie in the natural structure, condition, and strength or stretching of the ligaments (vev́owv), associated with fluid, so that, with respect to femur dislocation, if it does not remain [in place], this happens not because the ligament (vevoov) [of the femoral head] is torn, but because of the natural weakening or stretching of the liga-

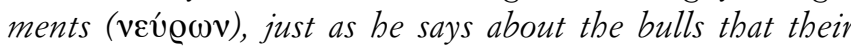
joints are mobile by nature». In Hipp. de art. (53).

In this fragment, the author agrees with the views of Heraclides and Hippocrates, noting the possibility of lengthening, weakening of strength and elasticity of LT. Apollonius of Citium talks (already with confidence) about the possibility of pathological changes in LT and transformation of its geometric and mechanical properties. These changes, registered over 2000 years ago, are still the cause of differences in the description of normal LT. It should also be noted that Apollonius of Citium says, like Hippocrates, that ligaments, and hence LT, are present in animals (cf. De artic. 8, 14-15; 52; Vectiar. 5, 5-6) (39).

Another mention of LT is found in the Roman anatomist and physician Rufus of Ephesus (I-II cent. AD). Speaking about the names of different body parts in the treatise $D e$ appellationibus partium corporis bumani, he writes:

«The name of pelvis (ioxiov) [is given to] the ligament (vevoov) that attaches to acetabulum and secures the entire joint» (54).

The statement by Rufus suggests that the author was aware of the existence of LT, its attachment to acetabulum and its connective function.

\section{Galen and the Byzantine authors}

Galen, who, along with Hippocrates, had remained the main authority in the field of anatomy until the time of Andreas Vesalius, mentions LT in a number of his treatises. In one of his early essays, On Bones for Beginners, written for those who are just beginning to study anatomy, Galen, explaining the structure of $\mathrm{HJ}$, says:

«There is a socket of large size in each of the ischia, attached by

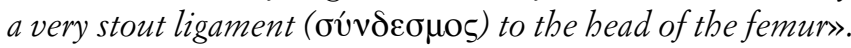

De oss. ad tir. XX, 2 (41).

This quote is interesting in that Galen notes, like the previous authors, that LT is attached directly to the bones that form $\mathrm{HJ}$, and not to its capsule or transverse acetabular liga- 
ment. He also specifically mentions the considerable strength of LT, which was not pointed out by his predecessors. This can be explained by the fact that this anatomical element was personally studied by Galen in somatically healthy young people who died in battle, i.e. physically well-developed warriors and gladiators (which is currently impossible for ethical reasons). The latest information on the low mechanical strength of LT, refers, as a rule, to senior persons (55-58). In his main work on anatomy, On Anatomical Procedures, Galen gives a more detailed description of the structure of HJ and LT yet:

«As with the arm you examined the ligaments of the bones, so now examine those of all the exposed joints and first of

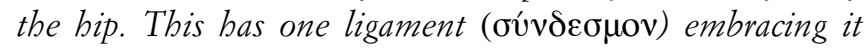
[capsular ligament], as with all joints. A second, bidden in the depths of the joint [ligamentum teres], ties the head of the femur to the hollow in the hip-bone [acetabulum]. It is

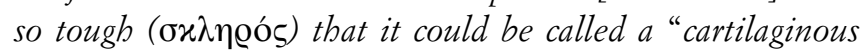

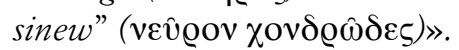

De anat. adm. II, 10 (41,59).

By the "ligament embracing the hip" Galen clearly means the HJ capsule (capsula articularis) with the external ligaments woven into it. The word "tough" describes the tension and high elastic modulus of LT (57). In the described specimen, Galen encountered LT of the "cartilage consistence”. Modern histological studies have established that "near their attachments the structure of ligaments undergoes a transition into fibrocartilage [...] and the fibroblasts become encapsulated and resembled chondrocytes" (60).

Galen provides a detailed description of LT in his work on physiology On the Usefulness of the Parts of the Body:

«In the femoral joint Nature created a ligament ( $\sigma u ́ v \delta \varepsilon \sigma \mu \mathrm{s}$ ), which is round, very strong, extending from the femoral head and connecting in the middle with the acetabulum, but did not create this in the shoulder joint, arranging it so that it could perform various movements».

De usu part. XII, 5, 17 (41).

This quotation from Galen echoes the statement made by Hippocrates in the treatise Instruments of Redactions $(\mathbb{S} 1)$, where he also compares the anatomical features of $\mathrm{HJ}$ and the shoulder joint. Galen was undoubtedly familiar with this treatise by Hippocrates, although he left no comment

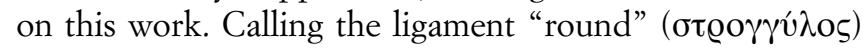
(lat. teres, rotundum), Galen must have meant not only the cross-sectional shape of LT, but also the interweaving of thin fibers, the fibrils of its stroma, since the Greek verb

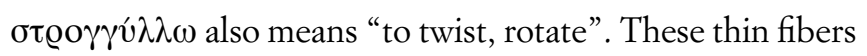
or, more precisely, bundles of fibers, were observed by Galen in ligaments and nerves.

Two more references to LT are found in Galenic Commentary on Hippocrates' On Joints, considered as one of the earlier works compiled between 177 and $180 \mathrm{AD}$. In the third chapter of the first Galen's comment we read:

«The femur has a small head and an elongated neck. It is located in the acetabulum, which is [quite] deep and surrounded by protruding edges; and at the top of its head

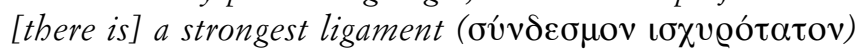
connecting with the acetabulum in the deepest place. That is why the femur is rarely dislocated as opposed to the shoulder that has no ligament ( $\sigma u ́ v \delta \varepsilon \sigma \mu o v$ ) and does not enter a deep cavity».

In Hipp. de art. I, 3 (41).

This passage, as the ones before it, refers to the writings of Hippocrates, namely, to the treatise On Joints (De artic., 79) and Instruments of Redactions (Vectiar., 42), in which the articular cavity of the shoulder joint is compared to the one of the HJ (39). The above quote shows that Galen had a good idea of the structure of $\mathrm{HJ}$ and distinguished acetabular labrum as well as its "deepest place" - acetabular fossa. He also notes the strength of LT and one of its functions, the retention of femoral head in acetabulum.

In the fourth Galenic Commentary on Hippocrates' On Joints, $\$ 40$, entitled "How to correct hip dislocation when it is dislocated inward," the author writes this about HJ:

«In this joint, the ligament [of the femoral head] is extremely strong, rounded and hidden in it, connecting the top of the femoral head with the deepest inner part of the acetabulum. Therefore, without even seeing the ligament itself, but based only on this reasoning, we can understand that it is short: since the hip always rotates - as Hippocrates said: "it rotates in the pelvic bone" - and never leaves the acetabulum, the ligament ought to be very short. And so, it is the ligament that prevents the hip from being dislocated, at least while it is in its natural state. And not only can the ligament rupture, but also, due to the abundance of fluid that has unnaturally accumulated in the cavity [joint], become so stretched that it sometimes allows the femur to dislocate from its natural place. And if, due to a rupture of the ligament, the bip is dislocated, then even with immediate reduction it will not be able to remain in its place. $<\ldots>$ This is how the nature of things teaches us that with a torn ligament, the reduction of femur cannot remain in its place. It should also be added that on the outside of the knee joint there are several tendinous ligaments and in the hip joint there is only this ligament, since neither anything of this kind, nor any muscles support 
the joint from the outside. <...> And Hippocrates himself said at the beginning of this book that even in bulls it is the hip that get dislocated when they grow old and lose weight, because when the ligament of the hip is torn, the thigh joint cannot remain in its place even after reduction, the thing that especially applies to the emaciated [animals].

Next, let's look at what can happen if the ligament, weakened due to the abundance of fluid [in the joint], allows the bip to dislocate, but then is reset. It seems to me that it is quite obvious that in the presence of fluid the joint will dislocate again, and when it dries up, it will regain its natural strength. And the fact that dislocation of the hip can happen due to the fluid can be learned from Hippocrates himself, who writes in the "Aphorisms" thus: "Whoever, due to the chronic sciatica, has the femoral head dislocated and reset again, will have an accumulation of mucus formed there". And when mucus builds up in the joint, then the ligament softens and weakens as a result. And it does not matter whether you call it a ligament

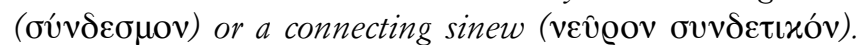
For those ligaments that have a rounded shape like tendons are usually called connecting sinews by anatomists. And we have already cured this kind of hip dislocation twice, and it did not dislocate again. Drying medications should be applied over the joint for a long time until the connective sinew is dry enough to stop stretching together with the femur extending beyond the edge of the acetabulum and keep it in its natural position». In Hipp. de art. IV, 40 (41).

Such an extensive quotation is provided in view of its exceptional significance. Here Galen describes in detail the geometric and mechanical properties of LT, its topographic anatomy and function. Regarding the attachment areas, the author notes that LT connects with the bones, that is, with the femoral head and the inside of the acetabulum (In Hipp. de art. IV, 40; cf. ibid. I, 3) (41), undoubtedly meaning acetabular fossa (lat. fossa acetabuli). Perhaps it is from this treatise that the term "round ligament" (lat. ligamentum teres, ligamentum rotundum) first entered the academic vocabulary and is still very much in use.

The author also dwelled on the pathology, that is, a rupture resulting from a traumatic hip dislocation and its "weakening" due to accumulation of pathological fluid, possibly implying synovitis. Galen also informs us of his own successful experience in treating a (presumably) recurring hip dislocation in children. Here we find, for the first time in history of medicine, a description of the conservative treatment of LT pathology. Galen in this case used some "drying medications", possibly in the form of compresses or ointment dressings, which, according to his clinical plan, "dried" the LT, eliminating its hyperelasticity, and was conducive to its contracting.
Galen's texts were well known to the Byzantine medical authors, who composed various kinds of encyclopedic codices and compendia containing extracts from the writings of ancient physicians, mainly Hippocrates and Galen. So, for example, Oribasius (IV-V cent.), when describing the structure of the femur in his essay "Medical Collections" (Coll. Med. XXV, 19) gives an exact quote from the aforementioned Galen's treatise On Bones for Beginners (41).

Important refinements in the description of the structure of LT are also found in the Pseudo-Galen's treatise Introduction, or the Physician:

«The hip has one bone. And its head, somewhat curved, enters the deep acetabulum of the pelvis; and it is connected by a sinew (vev́ow), growing from the middle of this cavity and growing into the middle of the femoral head».

Introd. s. Med. XII $(41,61,62)$.

It should be noted that in this case, Pseudo-Galen, in

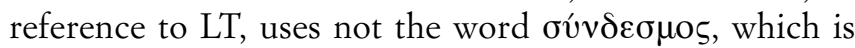
more characteristic of Galen, but the old term vevoov, which was employed by his predecessors Hippocrates, Heraclides of Tarentum, Hegetor, Apollonius of Citium and Rufus of Ephesus. Apparently, Pseudo-Galen was well versed in the normal anatomy of $\mathrm{HJ}$, as he correctly describes the significant depth of acetabulum and the attachment of LT to its middle, that is, to the bottom of acetabular fossa. The latter circumstance is extremely important for biomechanics of $\mathrm{HJ}$, since only with this type of connection can LT fully perform its important functions: limiting movements, supporting the pelvis, the hip abductor muscle group and the upper part of the femoral head $(15,17,23)$.

Another description of LT, similar to Galen's, is found in the works of Byzantine physician Theophilus Protospatharius (circa VII cent.), who, in book V of the treatise On the Construction of the Human Being, wrote:

«For the sake of this, the kindness and creation of God grew from the bottom of the acetabulum a round sinew (vevo@ov),

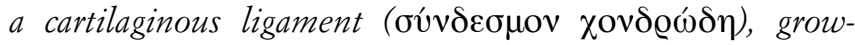
ing into the head of the femur and holding it there to avoid dislocation».

$$
\text { De corp. bum. fabr. XIII, } 204 .
$$

In the above passage, Theophilus Protospatharius does not provide any new information, but, undoubtedly under the influence of Galen, uses the epithet "round" and "cartilaginous", describing the beginning of LT from the bottom of acetabulum, and also agreeing with its role of holding the femoral head and preventing dislocation. 


\section{CONCLUSIONS}

Ancient physicians wrote predominantly in Greek, with medical literature in Latin being presented but scarcely, and terminology developed poorly (63). The term ligamentum in the anatomical meaning of "ligament" did not yet exist Latin literature. The word nervus, "sinew", was used to denote ligaments in Latin. By the end of the V century the four basic terms for LT that Galen mentions had

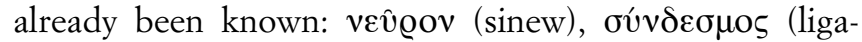

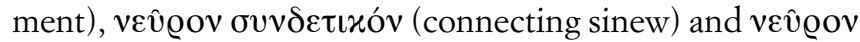

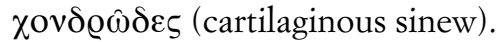

The physicians of the Classical period clearly established that LT was present in both humans and animals, charted its topographic anatomy, as well as established its main mechanical and geometric properties. In particular, they noted that it "is located in the acetabulum", and is "deeply hidden in the joint", for some authors it "grows from the femoral head", for others it "starts from the middle of the acetabulum". These physicians also drew attention to its mechanical properties, that is, very high strength, resilience, consistence (cartilage density) and, at the same time, flexibility, allowing movements of the femoral head. The geometric features were also indicated, in particular, that LT has a short length, and in shape it is "round". The latter characteristic described by Galen subsequently led to the emergence of the well-known Latin term for LT, i.e. "round ligament", which is still applied. Regarding the role of LT, it was noted that it connects the acetabulum with the femoral head and prevents its dislocation, that is, limits rotational and forward movements in $\mathrm{HJ}$.

In Palestine of the biblical times, it was believed that LT provided a normal gait, participating in the organization of this type of human locomotion, and an injury to it caused lameness. Ancient medical authors also knew about its traumatic rupture, and identified other types of LT pathology, in particular, "soaking", weakening (possibly a dystrophic change), stretching (that is, lengthening), suggested the possibility of its constriction (in other words, shortening) and drying (dehydration with increasing elasticity). The factors leading to pathological changes in LT were identified as trauma, namely hip dislocation, exhaustion, advanced age, and an excessive accumulation of "fluid" in HJ. For the treatment of LT pathology, the application of drying compresses was used. An injury to LT was seen as the cause of recurring hip dislocation. It was regarding this issue that the first correspondence discussion on LT took place, lasting five centuries and involving Heraclides of Tarentum, Hegetor, Apollonius of Citium and Galen of Pergamon.

\section{STRENGTHS \& WEAKNESSES}

\section{Strengths}

Our work based on an interdisciplinary approach, allowing us to propose a combination of linguistic and medical analysis of various Greek and Latin texts containing references to ligamentum teres. A linguistic analysis has enabled us to trace the transformation of the term from 5 cent. $\mathrm{BC}$ to 3 cent. $\mathrm{AD}$, as well as the history of the term, medical contexts of its usage, its etymology and its early synonyms. Due to descriptive study of different sources we have created a new field of researching and new questions to acquire a better understanding of how ancient authors considered normal and pathological anatomy of the ligamentum teres, its physical and geometric features to make possible a description of the conservative treatment of its pathology.

\section{Weaknesses}

Works of some ancient authors (Heraclides of Tarentum, Hegetor), which we have considered as genuine, preserved only in short fragments and quotations by the later writers, so that the genuineness of these works and our conclusions are still in question, and the information we have extracted from them is often suggestive rather than definitive. Not all of the passages we quoted (such as Galenus In Hipp. De art. IV, 40, ed. Kuhn XVIII A: 731-736) have been published in modern critical editions; an English translation of these passages are our own. Some authors reiterate or rethink the concepts of their predecessors, but we considered it necessary to present a complete collection of the quotations, providing them with comments.

\section{CONFLICT OF INTERESTS}

The authors declare that they have no conflict of interests.

\section{LIST OF ABBREVIATIONS}

- Apollonius:

In Hipp. de art. - In Hippocratis de articulis commentarius

- Aristoteles:

Hist. anim. - Historia animalium

- Celsus:

De med. - De medicina

- Galenus

De anat. adm. - De anatomicis administrationibus

De loc. aff. - De locis affectis

De motu musc. - De motu musculorum 
De usu part. - De usu partium

In Hipp. de art. - In Hippocratis librum de articulis et Galeni in eum commentarii IV

- Hippocrates:

De artic. - De articulis

De loc. in hom. - De locis in homine

Vectiar. - Vectiarius

- Oribasius:

Coll. med. - Collectiones medicae

- Plinius Major:

Hist. nat. - Historia naturalis

- Ps.-Galenus:

Introd. s. Med. - Introductio seu Medicus

- Theophilus Protospatharius:

De corp. bum. fabr. - De corporis bumani fabrica

\section{REFERENCES}

1. Netter F. Atlas of human anatomy. 6th ed. Philadelphia; Saunders Elsevier 2011;474.

InternetArchive

2. Waugh A, Grant A. Ross \& Wilson Anatomy and physiology in health and illness. Edinburg [etc.]; Elsevier Health Sciences 2014;418.

Google Books

3. Cerezal L, Arnaiz J, Canga A, et al. Emerging topics on the hip: ligamentum teres and hip microinstability. Eur J Radiol. 2012;81(12):3745-3754.

PubMed

4. Martin HD, Hatem MA, Kivlan BR, Martin RL. Function of the ligamentum teres in limiting hip rotation: a cadaveric study. Arthroscopy. 2014;30(9):1085-1091.

PubMed

5. Perumal V, Woodley SJ, Nicholson HD. Ligament of the head of femur: A Comprehensive Review of its Anatomy, Embryology, and Potential Function. Clin Anat. 2015;19(2):247-255.

PubMed

6. Brady AW, Mikula JD, Chahla J, et al. Anatomic analysis of the native ligamentum teres. J Hip Preserv Surg. 2016;3(1):hnw030.012.

GoogleScholar

7. Arhipov SV. Funkciya svyazki golovki bedrennoj kosti: obzor lit. Genij ortopedii. 2006;4:105-107. [in Russ.] eLIBRARY.RU

8. Wenger DR, Miyanji F, Mahar A, Oka R. The mechanical properties of the ligamentum teres: a pilot study to assess its potential for improving stability in children's hip surgery. J Pediatr Orthop. 2007;27(4):408-410.

PubMed
9. Wenger DR, Mubarak SJ, Henderson PC, Miyanji F. Ligamentum teres maintenance and transfer as a stabilizer in open reduction for pediatric hip dislocation: surgical technique and early clinical results. J Child Orthop. 2008;2(3):177-185.

PubMed

10. Lampert C. Läsionen des lig. capitis femoris: pathologie und therapie. Arthroskopie. 2009;22(4):293-298.

SpringerLink

11. Sutton JB. The nature of certain ligaments. J Anat Physio. $1884 ; 18: 225-238$.

PubMed

12. Kapandji IA. The physiology of the ligamentum teres. In: Kapandji IA, Ed. The physiology of the joints. Vol. 2. 2-nd ed. New York; Churchill Livingstone 1978.

GoogleScholar

13. Chen HH, Li KC, Li AFY, et al. Effects of ligamentum teres on the hip stability. Biomed Eng Appl Basis \& Comm. 1994;6:276-279.

GoogleScholar

14. Rao J, Zhou YX, Villar RN. Injury to the ligamentum teres. Mechanism, findings, and results of treatment. Clin Sports Med. 2001;20(4):791-799.

PubMed

15. Arkhipov SV. On the role of the ligamentum capitis femoris in the maintenance of different types of erect posture. Hum Physiol. 2008;34(1):79-85.

SpringerLink

16. Dodds MK, Lee J, McCormack D. Transarticular stabilization of the immature femoral head: assessment of a novel surgical approach to the dislocating pediatric hip in a porcine model. J Pediatr Orthop. 2008;28(1):36-42.

PubMed

17. Arkhipov SV, Zagorodny NV, Skvortsov DV. Ligamentum capitis femoris a pilot an experimental study. Am J Biomed Sci \& Res. 2019;5(2):92-94.

AmJBiomedSciRes

18. Bardakos NV, Villar RN. The ligamentum teres of the adult hip. J Bone Joint Surg. Br. 2009;91(1):8-15.

PubMed

19. Cerezal L, Kassarjian A, Canga A, et al. Anatomy, biomechanics, imaging, and management of ligamentum teres injuries. Radiographics. 2010;30(6);1637-1651.

PubMed

20. Botser IB, Martin DE, Stout CE, Domb BG. Tears of the ligamentum teres: prevalence in hip arthroscopy using 2 classification systems. Am J Sports Med. 2011;39(1) (Suppl):117S-125S.

PubMed

21. Byrd JW, Jones KS. Traumatic rupture of the ligamentum teres as a source of hip pain. Arthroscopy. 2004;20(4):385-391. 
PubMed

22. Haviv B, O'Donnell J. Arthroscopic debridement of the isolated Ligamentum Teres rupture. Knee Surg Sports Traumatol Arthrosc: Off J ESSKA. 2011;19(9):1510-1513.

PubMed

23. Arkhipov SV. Svyazka golovki bedrennoi kosti. Funktsiya i rol' v patogeneze koksartroza. Saarbrucken; Lambert Academic Publishing 2013. [in Russ.]

MoreBooks

24. O’Donnell J, Klaber I, Takla A. Ligamentum teres reconstruction: indications, technique and minimum 1-year results in nine patients. J Hip Preserv Surg. 2020;0(0):1-7. GoogleScholar

25. Arkhipov SV, Skvortsov DV. Ligamentum capitis femoris: first written mentions. MLTJ. 2019;9(2):156-164.

GoogleScholar

26. O'Donnell JM, Pritchard M, Salas AP, Singh PJ. The ligamentum teres - its increasing importance. J Hip Preserv Surg. 2014;1(1):3-11.

GoogleScholar

27. Rosinsky PJ, Shapira J, Lall AC, Domb BG. All About the Ligamentum Teres: From Biomechanical Role to Surgical Reconstruction. J Am Acad Orthop Surg. 2020; 28(8):e328-e339.

PubMed

28. Padulo J, Oliva F, Frizziero A, Maffulli N. Muscles, Ligaments and Tendons Journal - Basic principles and recommendations in clinical and field Science Research: 2018 update. MLTJ 2018;8(3):305-307.

GoogleScholar

29. Shchedrovickij D. Vvedenie v Vethij Zavet. I. Kniga Bytiya. Moskva; Terevinf 1994. [in Russ.]

GoogleScholar

30. Haudebert P (Ed.). Le Pentateuque: Débats et recherches. XIVe congrès de l'ACFEB, Angers (1991) (coll. Lectio divina, 151). Paris; Le Cerf 1992.

Persée

31. Bräumer H. Das erste Buch Mose. Bd. I. Wuppertaler Studienbibel. Reihe Altes Testament. Berlin; Evangelische Versandbuchhandlung O. Ekelmann Nachf 1986.

Booklooker

32. Brown F. The new Brown-Driver-Broggs-Gesenius Hebrew and English Lexicon. Peabody; Hendrickson Publishers 1979:161;674-675.

GoogleScholar

33. Jamieson R, Fausset AR, Brown D. Commentary Critical and Explanatory on the Whole Bible. Vol. I. Hartford; 1871. GoogleScholar

34. The Pulpit Commentary. / Ed. by H.D.M. Spence and J.S. Exell. Vol. I. New York, Toronto; Funk \& Wagnalls Company 1880.
InternetArchive

35. A Concise Hebrew and Aramaic Lexicon of the Old Testament. / By W.L. Holladay. Leiden; Brill 1988.

InternetArchive

36. Exposition of the Old and New Testament. / Ed. by J.

Gill. Vol. 1. London; 1748-1763.

WebArchive

37. Preuss J. Biblical and Talmudic Medicine. Transl. and ed. by Dr. F. Rosner. New York [etc.]; A Jason Aronson

Book, Rowman \& Littlefeld Publishers 2004.

GoogleBooks

38. André J. Le vocabulaire latin de l'anatomie. Paris; Belles letters 1991:208-209.

GoogleScholar

39. Oeuvres complètes d'Hippocrate / Par É. Littré. Vol. 1-10. Paris; 1839-1861 (repr. Amsterdam, 1961-1973).

HathiTrust

40. von Staden H. Herophilus. The Art of Medicine in Early Alexandria. Cambridge [etc.]; Cambridge University Press 1989:256.

GoogleBooks

41. Kühn CG. Claudii Galeni opera omnia. Leipzig; 18211833 (repr. Hildesheim, 1965).

HathiTrust

42. Garofalo I. Erasistrati fragmenta. Pisa; Gardini 1988.

GoogleBooks

43. Marcovecchio E. Dizionario etimologico storico dei termini medici. Firenze; Festina lente 1993:578.

GoogleScholar

44. Sutton JB. The nature of ligaments. Part IV. J Anat Physiol. 1885;20(Pt 1):38.1-75.

PubMed

45. Welcker $H$. Nachweis eines ligamentum interarticulare

("teres") humeri, sowie eines Lig. sessile Femoris. Z Anat Entwicklungsgesch. 1877;2:98-107.

GoogleScholar

46. Kolts I, Busch LC, Tomusk H, et al. Macroscopical anatomy of the so-called "rotator interval". A cadaver study on 19 shoulder joints. Ann Anat. 2002;184(1):9-14.

GoogleScholar

47. Reuther F. Anatomie, Biomechanik und Klassifikation der Schultergelenkverletzung. Trauma Berufskrankh. 2006;8(3):S241-S246.

GoogleScholar

48. Sabat D, Singh D, Kumar V, Gupta A. Open perineal dislocation of hip in a child. Eur J Orthop Surg Traumatol. 2009;19:277-279.

GoogleScholar

49. Muzaffar N, Hafeez A, Bashir N, Singh S. Open anterior hip dislocation in a young adult with exposed femo- 
ral head and no neurovascular damage. Malays Orthop J. 2012;6(1):40-42.

PMC

50. Arkhipov SV, Prolygina IV. Galen o vyvikhe bedra i svyazke golovki bedrennoi kosti. Opera medica historica. Trudy po istorii meditsiny. Al'manakh ROIM. Vypusk 4. Moskva; 2019:89-96. [in Russ.]

ResearchGate

51. Schaumkel JV, Villar RN. Healing of the ruptured ligamentum teres after hip dislocation-an arthroscopic finding. HIP Int. 2009;19(1):64-66.

GoogleScholar

52. Davarinos N, Bonvin A, Christofilopoulos P. Ligamentum teres reattachment post-surgical dislocation of the hip: a case report. Regenerative capacity reaffirming its greater role in hip stability and function? J Hip Preserv Surg. 2017;4(4):337-340.

GoogleScholar

53. Kollesch J, Kudlien F. Apollonii Citiensis In Hippocratis De articulis commentaries; ediderunt J.Kollesch et F.Kudlien, in linguam Germanicam transtulerunt J.Kollesch et D.Nickel. Berolini; in aedibus Academiae Scientiarum 1965.

CMG

54. Daremberg Ch, Ruelle Ch. Oeuvres de Rufus d'Ephèse.

Paris; 1879.

GoogleBooks

55. Podrushnyak EP. Vozrastnye izmeneniya sustavov cheloveka. Kiev; Zdorov'ya 1972. [In Russ.]

GoogleScholar

56. Chen HH, Li AF, Li KC, Wu JJ, Chen TS, Lee MC. Adaptations of ligamentum teres in ischemic necrosis of human femoral head. Clin Orthop Relat Res. 1996;328:268-275.

PubMed
57. Philippon MJ, Rasmussen MT, Turnbull TL, et al. Structural Properties of the Native Ligamentum Teres. Orthop J Sports Med. 2014;2(12):2325967114561962.

PubMed

58. Perumal V, Scholze M, Hammer N, Woodley S, Nicholson H. Load-deformation properties of the ligament of the head of femur in situ. Clin Anat. 2019:1-9.

GoogleScholar

59. Singer C. Galen: On Anatomical Procedures (I-IX 6). London [etc.]; Oxford University Press 1956.

InternetArchiv

60. Ham AW. Histology. Philadelphia, Toronto; J.B. Lippincott Company 1974.

InternetArchive

61. Everett N. The Alphabet of Galen: Pharmacy from Antiquity to the Middle Ages: a Critical Edition of the Latin text with English translation and commentary. Toronto [etc.]; University of Toronto Press 2012.

GoogleBooks

62. Petit C. What does pseudo-Galen tell us that Galen does not? Ancient medical schools in the Roman Empire. In Philosophical themes in Galen. Eds. P. Adamson, R. Hansbeger, J. Wilberding. London; The Institute of Classical Studies University of London 2014:269-290.

GoogleScholar

63. Langslow DR. Medical Latin in the Roman Empire. Oxford; University Press 2000.

GoogleBooks 